\title{
LIST OF ROLF NEVANLINNA'S PUBLICATIONS
} prepared by ILPPO SIMO LOUHIVAARA

This index supplements the list of Rolf Nevanlinna's publications from the years 1919-1976 which appeared in the volume Commentationes in honorem Rolf Nevanlinna LXXX annos nato (Annales Academiæ Scientiarum Fennicæ. Series A. I. Mathematica. Volumen 2, 1976, pp. VII-XXV). It contains the papers and articles published after the completion of the earlier index. In the preparation of the list, the same rules have been followed as in the previous time.

1976

Theory and application in exact science. Bull. Math. Soc. Sci. Math. R. S. Roumanie (N. S.) 20 (68). S. 303-306.

1977

Alexander Dinghas in memoriam. [Deutsch.] Ansprachen und Vorträge des Gedenkkolloquiums für Professor Dr. phil. habil. Alexander Dinghas am 20. Juni 1975 an der Freien Universität Berlin. [Hektographiert.] Herausgegeben von H. BEGEHR. Freie Universität Berlin, Fachbereich Mathematik, I. Mathematisches Institut, Berlin. S. 36-39.

Kokeista ja ajatuskokeista. [Über Experimente und Gedankenexperimente.] Ajatus ja analyysi. [Idee und Analyse.] Toimittaja [Herausgeber] TAUno NybERG. Taskutieto 134. Werner Söderström osakeyhtiö, Porvoo-Helsinki-Juva. S. 83-95. ISBN 951-0-07318-0.

Randbemerkungen zum Begriff der Realität. Logik, Mathematik und Philosophie des Transzendenten. Festgabe für Uuno Saarnio zum achtzigsten Geburtstag. Unter Mitwirkung von Heinz Enders, Raili Kauppi, Sven Krohn und Tapio AнокALlio herausgegeben von Ahti HaKamies. Verlag Ferdinand Schöningh, München-Paderborn-Wien. S. 61-66. ISBN 3-506-73611-6.

- - \& Paul Edwin Kustannheimo. Grundlagen der Geometrie. (I. Teil: Affine Geometrie der Ebene von Rolf Nevanlinna. II. Teil: Finite Geometrien von Paul E. Kustaanheimo.) [Zweite, durchgesehene Auflage.] Lehrbücher und Monographien aus dem Gebiet der exakten Wissenschaften. Mathematische Reihe 43. Birkhäuser Verlag, Basel-Stuttgart. 135 S. (S. 11-89, 91-127.) ISBN 3-76430958-X. 
1978

[R. H. N.] Lindelöf, Ernst. [Finnisch.] Otavan suuri ensyklopedia 5. Kustannusosakeyhtiö Otava, Helsinki. S. 3752. ISBN 951-1-02232-6 [ganzes Werk], 951-1-04827-9 [5. Band].

On the minimalmodulus of an entire function. Комплексный анализ и его приложения. Сборник статей, Посвящается академику Илье Несторовичу Векуа к его семидесятилетию. [Komplexe Analysis und ihre Anwendungen. Sammlung von Arbeiten, Gewidmet dem Akademiemitglied Il'ja Nestorovič Vekua zu seinem 70. Geburtstag.] Академия наук СССР, Ордена Ленина математический институт имени В. А. Стеклова. Издательство «Наука», Москва. S. 418-420.

1979

Musiikkimuistoja. [Erinnerungen über Musik.] Ihminen musiikin valtakentässä. Juhlakirja Professori Timo Mäkiselle 6. 6. 1979. [Der Mann im Bereich der Musik. Festschrift für Professor Timo Mäkinen am 6. Juni 1979.] Toimittanut [Herausgegeben von] Reijo Pajamo. Jyväskylä Studies in the Arts 11. Jyväskylän yliopisto, Jyväskylä. S. 154-159. ISBN 951-678-166-7. ISSN 0075-4633.

1980

Fysiikan variaatioperiaatteet. [Variationsprinzipien der Physik.] [Hektographierte Vorlesungsausarbeitung.] University of Helsinki, Research Institute for Theoretical Physics, Internal Report 2-80. Helsinki. 3+74 S. ISBN 951-45-2033-5.

[R. H. N.] Riemann, Bernhard. [Finnisch.] Otavan suuri ensyklopedia 8. Kustannusosakeyhtiö Otava, Helsinki. S. 5729-5730. ISBN 951-1-02232-6 [ganzes Werk], 951-1-05637-9 [8. Band].

[R. H. N.] Suhteellisuusteoria. [Relativitätstheorie.] Otavan suuri ensyklopedia 8. Kustannusosakeyhtiö Otava, Helsinki. S. 6485-6487. ISBN 951-1-02232-6 [ganzes Werk], 951-1-05637-9 [8. Band].

$\ddot{U}$ ber rationale Approximation meromorpher Funktionen mit dem totalen Defekt 2. Vorträge, gehalten am 9. Dezember 1977 auf dem Festkolloquium zum Anlasse des 70. Geburtstages von Prof. Dr. Dr. h. c. Ernst Peschl am Mathematischen Institut der Universität Bonn. Bonn. Math. Schr. 121, Sonderband. S. 33-40. 